\title{
Contribuições de um curso de formação continuada observadas na prática pedagógica de professores ${ }^{1}$
}

Maria Gracilene de Carvalho Pinheiro* Angélica da Fontoura Garcia Silva**

Ruy César Pietropaolo***

*Doutoranda do Programa de Pós-graduação em Educação Matemática da Universidade Anhanguera de São Paulo (Unian-SP)

gracilenepinheiro@gmail.com

**Professora do Programa de Pós-graduação da Unian-SP angelicafontoura@gmail.com

***Professor do Programa de Pós-graduação da Unian-SP rpietropaolo@gmail.com
Resumo: 0 presente artigo tem como propósito destacar as contribuições de um curso de formação continuada para a prática pedagógica de professoras ao ensinar frações a alunos dos anos iniciais do ensino fundamental. A formação desenvolveu-se no contexto do Observatório da Educação com um grupo de docentes da rede estadual de São Paulo. A investigação, de natureza qualitativa, realizou-se em três fases: aplicação de questionários preliminares, intervenção, entrevista e observação de aula. Apresenta-se, aqui, a análise relativa às aulas ministradas por três participantes do curso um ano após o término da formação. Observou-se que houve mudanças no modo como as docentes passaram a abordar o conteúdo, no que se refere à exploração de ideias relativas ao significado de quociente, a partir de situações parte-todo, estabelecendo relações importantes entre os dois significados discutidos. Concluiu-se que a formação contribuiu significativamente para a (re)construção dos conhecimentos acerca desse conceito pelas professoras investigadas.

Palavras-chave: Políticas públicas governamentais. Pibid. Formação docente.

Agradecemos o apoio financeiro recebido da Coordenação de Aperfeiçoamento de Pessoal de Nível Superior (Capes) - Brasil, por meio do Projeto Observatório da Educação (Convênio ou AUXPE n.ํ: OE 2050/10), bem como a disponibilidade das escolas parceiras deste projeto. 


\section{INTRODUÇÃO}

Nesta comunicação pretendemos analisar as contribuições observadas na prática docente de professoras participantes de um processo formativo ${ }^{2}$. 0 grupo era composto por 18 professoras que lecionavam matemática para os anos iniciais do ensino fundamental de escolas públicas estaduais de São Paulo, mas para este estudo analisamos a prática de três delas, professoras Ana, Renata e Marcela ${ }^{3}$. Nossa escolha se deve ao fato de que essas docentes participaram de todas as sessões de formação e também por terem aceitado desenvolver, em sala de aula, com seus alunos, em um dado momento da formação, atividades relativas ao tema em estudo - frações ${ }^{4}$.

Apresentamos, inicialmente, resultados de algumas pesquisas anteriores à nossa, que discutem questões relativas tanto à formação quanto aos processos de ensino e de aprendizagem das frações, e que, a nosso ver, justificam a relevância deste estudo. Explicitamos a base teórica adotada na análise das informações produzidas no decorrer desta investigação e fazemos uma breve descrição do estudo, apresentando os procedimentos metodológicos, a análise e a discussão dos dados obtidos pela observação da prática pedagógica das professoras identificadas no parágrafo anterior. Por fim, tecemos nossas considerações acerca dos resultados do estudo em questão e apontamos algumas de suas limitações.

\section{RELEVÂNCIA: O QUE DIZEM AS PESQUISAS}

Discussões relativas à construção do conceito de frações realizada por alunos e até mesmo por seus professores têm sido foco de investigações tanto no Brasil como em outros países. Estudos como os de Nunes e Bryant (2009), Cardoso e Mamede (2009), Campos, Jahn, Leme da Silva e Silva

2 O mesmo constitui parte de uma pesquisa de mestrado em Educação Matemática desenvolvida sob o título: Formação de professores dos anos iniciais: conhecimento profissional docente ao explorar a introdução do conceito de fração, realizada no contexto do Projeto Observatório da Educação Auxílio número 99/2010 - projeto de pesquisa e formação desenvolvido na Universidade Anhanguera de São Paulo (Unian-SP) e financiado pela Coordenação de Aperfeiçoamento de Pessoal de Nível Superior (Capes).

3 Para preservar o anonimato dos nossos sujeitos de pesquisa, os nomes apresentados são fictícios.

4 Utilizamos o termo fração para designar os números racionais na representação fracionária. 
(1995), Rodrigues (2005), Damico (2007), Garcia Silva (2007), Monteiro Cervantes (2010), Campos (2011), Canova (2013), dentre outros, apontam inúmeras dificuldades observadas em alunos e em professores em relação à compreensão de frações.

Por exemplo, em estudo realizado por Garcia Silva (2007) com alunos do 50 ano do ensino fundamental, foram evidenciadas dificuldades relativas aos diferentes significados das frações e seus invariantes. Isso também foi constatado por Rodrigues (2005) com alunos que estudavam no final da escola básica (17, 18 anos). 0 autor observou que tais estudantes ainda apresentavam dificuldades significativas tanto na compreensão do papel da unidade de referência, em problemas envolvendo frações, como sobre as peculiaridades das situações envolvendo grandezas discretas.

A investigação de Garcia Silva (2007) concluiu ser o conhecimento profissional docente um dos fatores que exerce influência sobre o processo de desenvolvimento profissional dos professores investigados. Ao analisar depoimentos de professores participantes em um processo de formação continuada sobre o ensino de frações, essa pesquisadora identificou também a relação entre o domínio do conteúdo e a prática pedagógica dos sujeitos envolvidos, observando que

[...] as limitações nos procedimentos de ensino foram acarretadas pelo fato de as docentes terem um domínio não suficiente do conteúdo a ser ensinado. Este fato pode ter impedido que os professores percebessem a possibilidade de variações da metodologia utilizada (GARCIA SILVA, 2007, p. 272).

$\mathrm{Na}$ literatura, observamos que pesquisas mais recentes apontam que 0 problema ainda continua. Campos (2011), por exemplo, afirma que "O ensino e a aprendizagem de frações constituem um obstáculo considerável para professores e alunos, desde o $4^{\circ}$ ano do ensino fundamental no Brasil, quando esse tema é abordado" (CAMPOS, 2011, p. 1).

Nunes e Bryant (1997), ao discutirem tal problemática, chamam a atenção sobre a forte tendência dos professores em trabalhar o conceito de fração utilizando principalmente o significado parte-todo. Seus estudos consideram que há relação entre as dificuldades encontradas pelos estudantes e a forma como se dá o ensino, com ênfase apenas a esse significado:

[...] que esta lacuna [referindo-se às dificuldades dos estudantes] seja uma consequência da aprendizagem do aluno de linguagem fracional na escola simplesmente através do procedimento de dupla contagem (NUNES et. al., 1997, p. 212-213). 
Todavia, estudos como os de Strefland $(1984,1991,1997)$ sugerem que a introdução do ensino de frações pelo quociente permite que ocorram situações nas quais o aluno apresenta maior compreensão desse conceito. Além dessas, outras investigações como as de Mamede (2007), Nunes et al. (2007), Nunes e Bryant (2009), Canova (2013) também indicam que as crianças compreendem melhor o uso das frações pelo quociente do que por parte-todo.

Quanto à formação inicial de professores, estudos como o de Damico (2007), ao analisar o conhecimento de estudantes de licenciatura, apontam dificuldades no conhecimento didático relacionado ao ensino de frações.

Tais pesquisas colocam em evidência a relevância de investigaro conhecimento e sua relação com a prática de professores acerca de diferentes situações que dão sentido ao conceito de frações.

\section{FUNDAMENTAÇÃO TEÓRICA}

Com base nos resultados apontados tanto nessas pesquisas como em outras que compunham a nossa revisão de literatura, iniciamos nossa investigação buscando apoio na Teoria dos Campos Conceituais de Gerard Vergnaud (1990, 1993), que trata de aspectos que ajudam a compreender como um conceito é construído por meio de três conjuntos: de situações, de invariantes e das representações.

De acordo com essa teoria, entendemos que a compreensão de um conceito ou conteúdo não ocorre a partir de uma única experiência, nem em um único momento, mas em um longo período de tempo e a partir da experiência, maturidade e aprendizagem.

Ainda em relação às questões didáticas, tomamos como base as pesquisas de Nunes, Bryant, Pretzik, Hurry (2003). Esses pesquisadores, apoiados em Vergnaud (1990), propõem que a construção do significado de fração se dê por meio das situações parte-todo, quociente, quantidades intensivas e operador multiplicativo (NUNES et al., 2003).

No processo formativo, procuramos ampliar a compreensão dos professores, sujeitos deste estudo, sobretudo acerca de duas dessas situações, quais sejam: parte-todo e quociente. 
Nunes e Bryant (2009), apoiados em Behr et al. $(1983,1984)$ definem situações parte-todo como aquelas em que um todo é dividido em $n$ partes iguais, tomam-se uma ou mais partes e a fração correspondente estabelece uma relação entre as partes em que o todo foi dividido e as partes consideradas na situação. Dessa forma, o denominador indica em quantas partes iguais o todo foi dividido, ao passo que o numerador indica o número de partes referentes à situação. Um exemplo dessa situação pode ser um bolo dividido igualmente em 5 partes, das quais tomam-se 2 partes; a fração correspondente a essa situação é $\frac{2}{5}$, sendo que 2 e 5 são partes do bolo.

Por outro lado, situações quociente são definidas pelos mesmos pesquisadores como aquelas em que está presente a ideia de partilha na divisão. Nelas aparecem duas quantidades: o dividendo e o divisor. Estes representam tanto a divisão como o resultado dessa divisão. Por exemplo, se 3 chocolates são divididos igualmente para 5 crianças, a representação $\frac{3}{5}$ indica tanto a divisão (3 dividido por 5), como a quantidade que cada criança irá receber $\frac{3}{5}$.

Nossa pesquisa fundamentou-se também nos estudos de Shulman (1986), Ball, Thames e Phelps (2008) e Serrazina (1999, 2010), por meio dos quais foi possível realizar a análise das questões relativas à formação de professores e refletir sobre a prática pedagógica e o conhecimento profissional docente.

Ball et. al. (2008) estudaram a prática docente e, apoiados nas Categorias de Conhecimento para o Ensino definidas por Shulman (1986), criaram a Teoria do Conhecimento para o Ensino da Matemática (MTK). De acordo com essa teoria, alguns domínios são necessários para o ensino de matemática: o conhecimento do conteúdo da disciplina e o conhecimento pedagógico do conteúdo matemático.

Considerando nossa temática de investigação (frações) e as categorias de conhecimentos definidas por Ball, Thames e Phelps, nos inspiramos em Pereira $(2013)^{5}$ para apresentar nossa interpretação dos tipos de conhecimentos propostos por Ball, Thames e Phelps (2008) para o ensino de frações:

5 Pereira (2013), em sua tese, apresentou uma tabela que contém a interpretação dos tipos de conhecimentos propostos por Ball, Thames e Phelps (2008), além de exemplos dessas categorias relativos à equação. 
TABela 1 - Nossa interpretação das Categorias de Ball, Thames e Phelps (2008) REFERENTE AOS CONHECIMENTOS NECESSÁRIOS AO ENSINO DAS FRAÇÕES

Tipos de conhecimento

para o ensino de

matemática

\section{Conhecimento comum \\ do conteúdo}

Conhecimento

especializado

do conteúdo

\section{Conhecimento para o ensino de fração}

Como exemplo de caso que caracteriza o conhecimento básico necessário a todos os profissionais que estudaram matemática na escola, sejam professores ou não, consideramos a compreensão da representação de fração de grandezas contínuas e discretas; operações com frações. Exemplo: entender o significado matemático da expressão: receber $\frac{1}{3}$ de férias, ou $\frac{1}{4}$ de hora.

Como exemplo relacionado ao conhecimento que permite ao professor prever erros dos estudantes e identificar suas causas, justificando do ponto de vista da matemática, consideramos uma situação em que o estudante precise manter a unidade de referência. Solicitando aos estudantes que escrevam a fração que exprime a quantidade de bolo da figura a seguir como fração de bolo, certamente encontraremos alunos que indicarão $\frac{10}{12}$ em vez de $\frac{10}{6}$, provavelmente porque consideraram os pedaços de bolo como grandezas discretas e não contínuas.
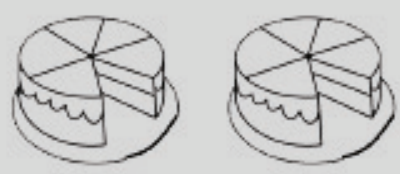


\section{Tipos de conhecimento \\ para o ensino de matemática}

Conhecimento de conteúdo e de alunos

Conhecimento de conteúdo e de ensino

Conhecimento de conteúdo e de currículo

\section{Conhecimento para o ensino de fração}

Como exemplo do conhecimento necessário para entender quais são os erros comuns aos alunos e propor novas estratégias de ensino, podemos citar o seguinte caso:

Um procedimento equivocado dos alunos para efetuar a adição de frações é adicionar numeradores e denominadores, respectivamente. Sabendo que os estudantes trazem do seu conhecimento intuitivo a ideia de metade, depois de identificar tal equívoco, o professor pode propor, por exemplo, fazer questões sobre "juntar" duas metades, e, em seguida, propor que eles efetuem a operação $\frac{1}{2}+\frac{1}{2}$ para comparar os resultados. Possivelmente os estudantes utilizarão o mesmo raciocínio e encontrarão $\frac{2}{4}, 0$ que os desestabilizará, pois sabem, mesmo que informalmente, que duas metades formam um inteiro ou $\frac{1}{2}+\frac{1}{2}=1$

Como exemplo do conhecimento de conteúdo e de ensino que relaciona a compreensão de conteúdos específicos da matemática com questões pedagógicas que podem interferir no processo de ensino e aprendizagem, podemos citar a compreensão da necessidade de trabalhar com os diferentes tipos de situações a fim de construir o conceito de fração.

Como exemplo do conhecimento que o professor deve ter do conteúdo e do currículo, podemos citar o conhecimento que ele tem de quais seriam as situações propostas para cada segmento de ensino em que o professor leciona. 
Ressalte-se que muitos estudos que antecederam o nosso apontam que, em geral, o significado parte-todo é o mais explorado pelos professores (Campos et al., 1995; Nunes e Bryant, 1997; Garcia Silva, 2007, dentre outros). Essas investigações indicam que o ensino baseado apenas nesse significado não é suficiente para a compreensão do conceito de fração, uma vez que na prática o procedimento parte-todo normalmente apoia-se apenas no "procedimento de dupla contagem" (NUNES e BRYANT, 1997, p. 212-213). Sendo assim, sugerem, fundamentados em Vergnaud (1990), que tal ensino deva abordar outros significados.

Nesse sentido, organizamos um curso de formação continuada que buscou refletir sobre os processos de ensino e de aprendizagem da fração, reunindo pesquisadores em Educação Matemática e professoras que ensinam matemática para os anos iniciais do ensino fundamental. Acreditávamos que seria possível investigar e ampliar os conhecimentos necessários ao ensino desse conteúdo das professoras participantes.

Nossa pesquisa foi desenvolvida em três fases: na fase preliminar, aplicamos dois questionários de caráter diagnóstico, por meio dos quais pretendíamos analisar quais eram os conhecimentos das professoras acerca do tema em estudo. A análise desses instrumentos possibilitou o planejamento e desenvolvimento da segunda fase, que foi destinada à intervenção, definida como processo formativo. Por fim, a terceira fase foi reservada às entrevistas e observações em sala de aula, com o objetivo de identificar contribuições do processo formativo na prática pedagógica das três professoras, sujeitos da pesquisa.

Neste artigo apresentaremos os resultados observados na terceira fase do estudo. Antes, porém, para melhor compreensão do leitor, descreveremos, de maneira breve, alguns resultados observados nas duas primeiras fases.

PRIMEIRA FASE DO ESTUDO: RESULTADOS EVIDENCIADOS NOS QUESTIONÁRIOS

Conforme descrito anteriormente, com base no referencial teórico adotado neste estudo, alguns saberes são necessários ao professor para o ensino de matemática: conhecimento do conteúdo da disciplina e o conhecimento pedagógico do conteúdo matemático (BALL; THAMES; PHELPS, 2008). 
A análise das informações colhidas na fase diagnóstica nos fez concluir que as professoras não vivenciaram, na sua formação inicial e em cursos de formação continuada, situações que lhes permitissem refletir sobre os processos de ensino e de aprendizagem das frações. Dessa forma, aquela seria a primeira oportunidade que essas professoras teriam de participar de um curso de formação sobre essa temática. Essa fase do estudo levou-nos a outras conclusões, a saber: a situação parte-todo era a única trabalhada pelo grupo em situação de ensino; de maneira geral, elas representavam corretamente as frações em situações parte-todo, porém não as reconheciam como um quociente e apresentavam dificuldades com os invariantes: ordem, equivalência e conservação da unidade de referência.

\section{SEgUNDA FASE DO ESTUdO: RESULTADOS EVIDENCIADOS} NO PROCESSO FORMATIVO

A intervenção foi desenvolvida em oito sessões de formação, durante as quais foi possível discutir e refletir sobre questões relativas à introdução do conceito de fração, utilizando os significados parte-todo e quociente. Nesse sentido, podemos afirmar que a formação ofereceu aos sujeitos deste estudo a oportunidade de vivenciar propostas diferenciadas de ensino desse tema. Durante as sessões de formação, as professoras puderam discutir sobre a sequência de tarefas elaborada por Nunes et al. (2009) como possibilidade para introduzir o ensino das frações a partir do significado quociente, bem como vivenciar outras atividades ${ }^{6}$ que lhes possibilitaram refletir sobre os invariantes ordem, equivalência e conservação da unidade de referência, cuja compreensão é fundamental para a construção do conceito de fração.

A sequência proposta por Nunes e Bryant (2009) foi desenvolvida também em sala de aula com alunos dos sujeitos investigados, o que possibilitou, no decorrer da formação, refletir também sobre as hipóteses levantadas acerca do pensamento do aluno e seus esquemas de resolução e propor encaminhamentos de estratégias didáticas que viessem a contribuir para a compreensão de ideias importantes inerentes ao conceito de fração.

6 Na formação propomos a vivência de atividades com a literatura infantil 0 pirulito do pato - livro de Nilson José Machado - para trabalhar o significado parte-todo. Além disso, fizemos uso do Tangram e a leitura e discussão de estudos que abordam questões relacionadas ao conceito de fração. 
Ao final dessa fase, analisando os depoimentos das professoras, manifestados durante a sua participação nas sessões de formação, pudemos observar que o curso proporcionou melhorias tanto no que se refere à compreensão do tema em estudo quanto no que diz respeito à percepção da possibilidade de aprimoramento da prática docente. Para buscar mais evidências sobre tais conclusões, entrevistamos as três professoras investigadas sobre o planejamento de uma aula introdutória de frações, que se constituiu como a terceira fase do nosso estudo. Apresentamos a seguir os resultados dessa fase.

Reiteramos que, decorrido um ano da formação, realizamos entrevistas com os sujeitos deste estudo e assistimos à aula que eles haviam preparado para introduzir o ensino de frações a seus alunos. Dessa forma, foi possível perceber contribuições da formação na prática pedagógica. Vale ressaltar que, sem nenhuma comunicação prévia entre elas, constatamos que as três professoras investigadas optaram por introduzir frações por meio da exploração do livro de literatura infantil $O$ pirulito do pato ${ }^{7}$, de autoria de Nilson José Machado (2003).

Para melhor compreensão do leitor sobre a análise dessa fase da investigação, achamos relevante descrever um pouco do que observamos no desenvolvimento dessa atividade.

A princípio, um fator que consideramos importante de ser evidenciado é que, de maneira geral, as três professoras iniciaram a aula utilizando-se das mesmas estratégias: apresentação da história em Power Point, seguida da leitura interpretativa.

Passado esse primeiro momento, as professoras Ana e Renata convidaram os alunos a interpretarem a história da divisão do pirulito. Para tanto, ofereceram papel com desenhos representando as partes em que o pirulito havia sido dividido e tesoura para que eles fizessem o recorte das partes, de acordo com a história, conforme retratam as imagens a seguir:

7 Trata-se de um livro de literatura infantil que descreve a história de dois patinhos que ganham um pirulito da mãe e têm que dividi-lo de formas diferentes à medida que chegam seus amiguinhos. 

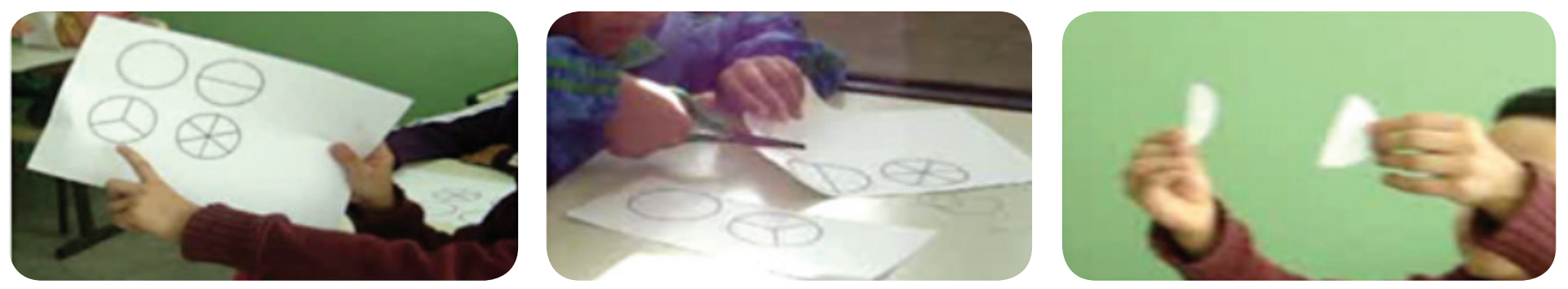

Figura 1 - Imagens vídeo: alunos realizando atividade sugerida pela professora Ana.

Na sequência, as professoras iniciaram a abordagem da ideia de fração. Chamou-nos a atenção o fato de as três professoras reunirem as ideias contidas nos significados parte-todo (esse era o significado trabalhado na história) e quociente. Observemos como isso ocorreu a partir do ensino, na descrição a seguir: "Existe uma coisa que se chama fração. Dá para a gente mostrar essa divisão do pirulito com números agora. A gente fez com papel e agora a gente vai fazer com números. Então olha só: quantos pirulitos tinham?" (professora Ana).

Nesse momento as crianças respondem que havia um pirulito. A professora faz o registro na lousa: “Um pirulito. Então olha: o número 1 [apontando para o registro que ela fez na lousa] [...] esse tracinho que a prô vai colocar aqui olha, ele significa dividido [apontando mais uma vez para o registro feito na lousa] (professora Ana).

Dessa forma inicia a leitura, apontando para os registros contidos na lousa “Então olha: um pirulito dividido...” (professora Ana), conforme imagens a seguir:

Figura 2 - Imagem vídeo 1: ensino desenvolvido pela professora Ana ${ }^{8}$.

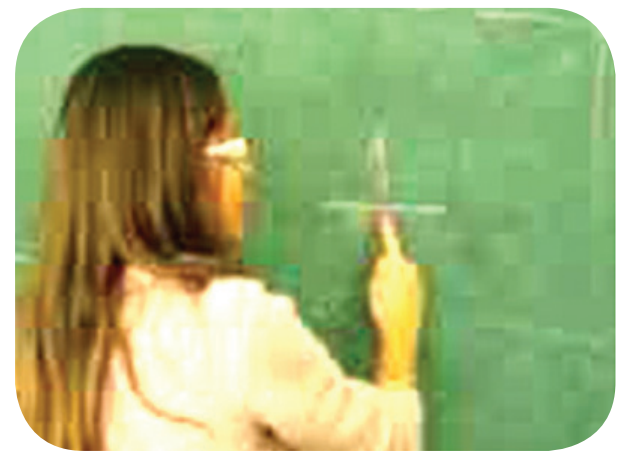

A professora dá continuidade reforçando a pergunta: "um pirulito dividido para quantos patinhos?" (professora Ana).

Quando as crianças respondem, a professora registra o algarismo 2, concluindo a representação da fração $\frac{1}{2}$. Em seguida, faz a leitura da representação fracionária: "um meio”, registrada pela imagem a seguir:

8 As imagens apresentadas neste artigo foram autorizadas pela professora conforme TCLE. 
Feito o registro da primeira quantidade fracionária, a professora segue problematizando, fazendo o registro de novas frações. Vejamos alguns trechos de como ela prosseguiu no ensino:

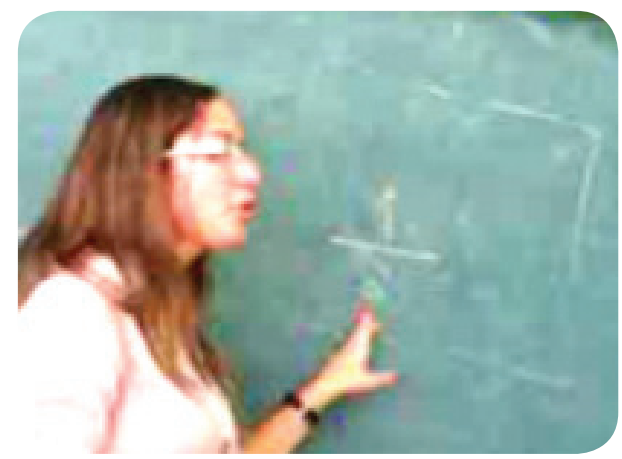

Figura 3 - Imagem vídeo 2: ensino desenvolvido pela professora Ana.

[...] se eu fosse dividir um pirulito para quatro crianças, como que eu iria colocar aqui? [referindo-se à forma de como fazer o registro da fração] Eu tenho um pirulito, como que eu mostro aqui em números? [...] Olha um pirulito [referindo-se ao registro que fez na lousa] [...] como que é o dividido? [referindo-se ao registro do traço que indica divisão] (professora Ana).

[...] em cima eu coloco o número de quê? De patinhos ou de pirulito? [e faz o registro na lousa]

[...] E isso aqui? O que que é esse traço? O que significa ele? [...] Então é o número de pirulito dividido por... [referindo-se ao registro da fração $\frac{1}{4}$ ] (professora Ana).

Vale ressaltar que a todo instante ela reforça a divisão do pirulito em partes iguais (ideia do parte-todo). Após registrar a representação de diferentes frações, a professora faz a ilustração com desenhos (ideia do parte-todo), como podemos observar na imagem a seguir:

Figura 4 - Imagem vídeo 3: ensino desenvolvido pela professora Ana.

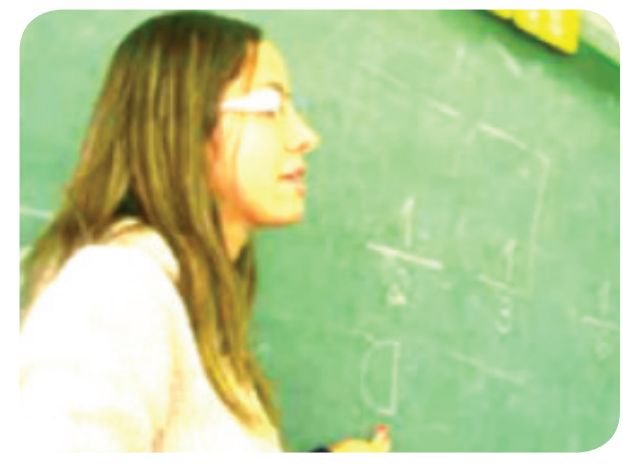

Estratégia de ensino semelhante foi observada nas aulas das professoras Renata e Marcela. A professora Marcela, por exemplo, durante o ensino, faz alguns questionamentos às crianças: “[...] como é que eu escrevo um inteiro dividido em dois? [...] se for dividido em três? [...] dividido em quatro? [...] dividido em cinco? Em seis? Se dividido em sete? E em dez?” (professora Marcela). 
A professora Renata, antes de iniciar o registro das quantidades fracionárias que apareciam na história, fez junto com as crianças o recorte do que representava cada parte (ideia de parte-todo).
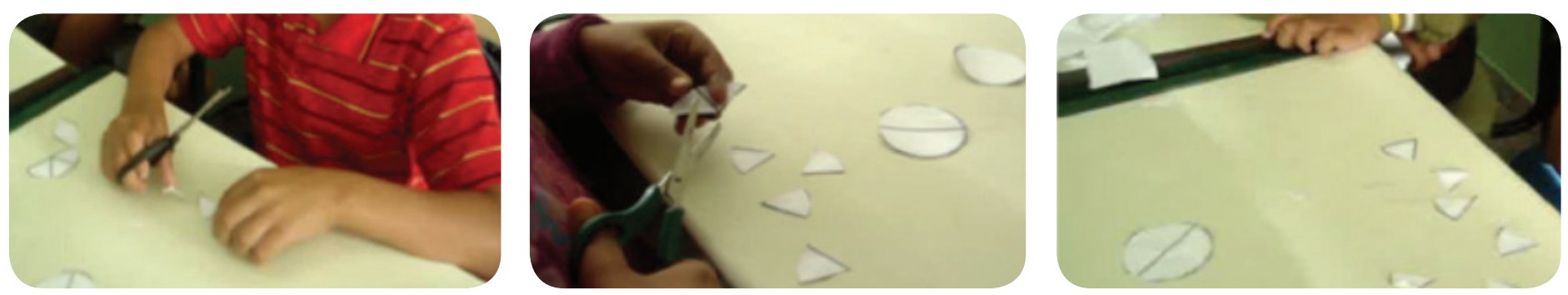

Figura 5 - Imagens vídeo: alunos realizando atividade sugerida pela professora Renata.

Em seguida, iniciou o registro. Vejamos trechos do ensino: "[...] e como que eu represento aqui? Um pirulito dividido por três? Como é que eu faço? Como é que eu ponho?" [referindo-se à forma de como escrever a representação da fração] (professora Renata).

As crianças responderam que ela deveria escrever o algarismo um (1) e indicar a divisão com um traço abaixo do algarismo. A professora então questiona: “Ah! Se eu colocar esse risco assim, significa que é dividir?" (professora Renata). As crianças confirmam.

Dessa forma, ela inicia o registro na lousa, sempre dialogando com os alunos: "Este um aqui em cima significa que eu tenho um pirulito. Aqui significa o quê? Esse risco. Esse risco significa o quê? [...] Um pirulito dividido por... dois" (professora Renata), conforme ilustram imagens a seguir:
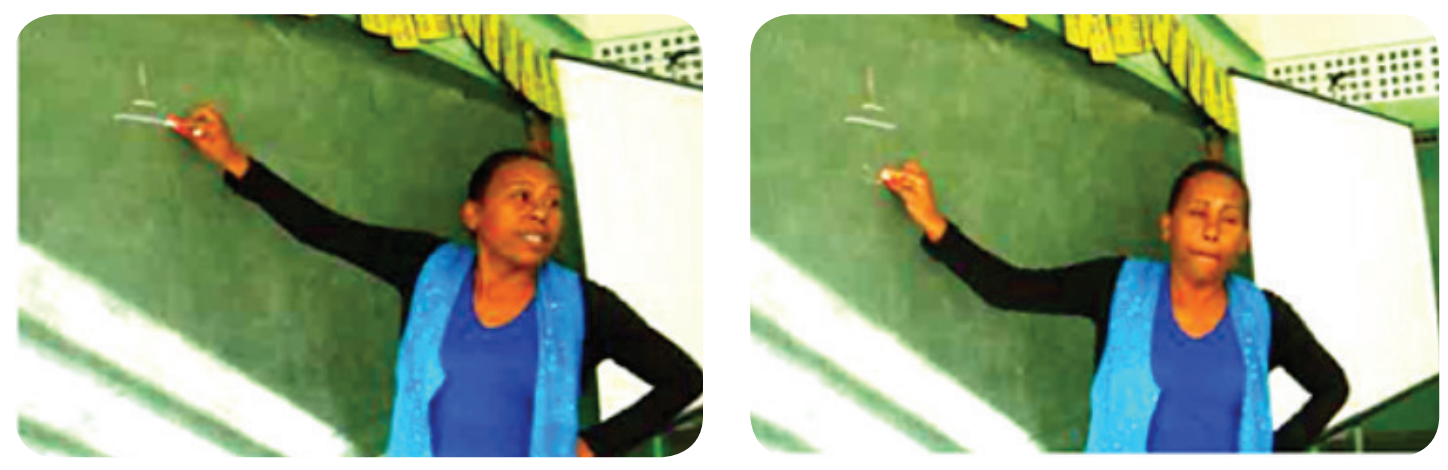

Figura 6 - Imagens vídeo 1: ensino desenvolvido pela professora Renata.

A professora dá continuidade ao ensino, exemplificando a divisão do pirulito entre as crianças, de modo a fazer a representação de várias frações. Um ponto interessante, observado na aula da professora Renata e que não foi 
explorado nas aulas das demais professoras é que ela iniciou o ensino sobre a equivalência entre as quantidades fracionárias, uma vez que durante a construção das representações fracionárias, chamou a atenção dos alunos para a correspondência existente entre as partes que representavam terços e sextos do pirulito de maneira que eles puderam perceber que um terço representa o mesmo que dois sextos: “[...] então foi um sexto. Significa que tanto o Mateus como a Sabrina receberam um sexto do pirulito [...] essas duas partes juntas é uma parte dessa? [referindo-se aos pedaços de sextos e terços]" (professora Renata).

As imagens a seguir ilustram esse momento do ensino:
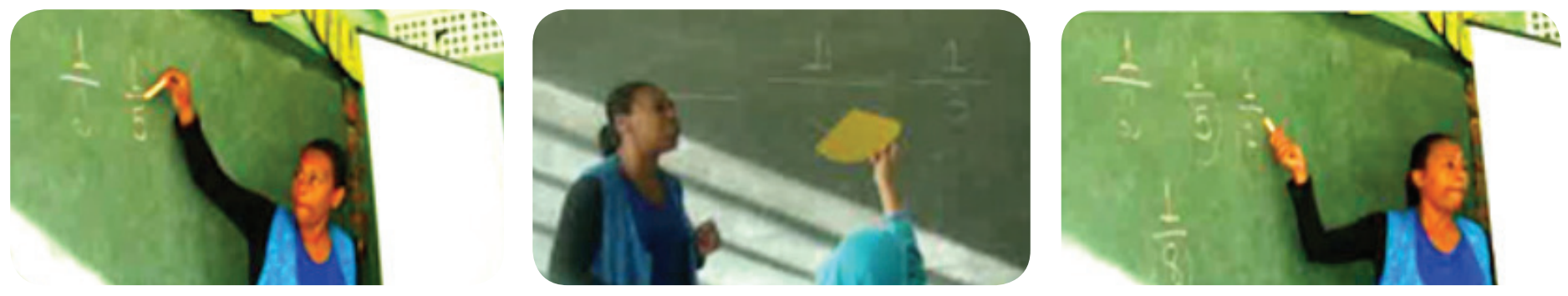

Figura 7 - Imagens vídeo 2: ensino desenvolvido pela professora Renata.

\section{DISCUSSÃO DOS RESULTADOS}

Diante das informações produzidas ao longo da investigação, podemos afirmar três aspectos que consideramos importantes, confirmando o que já descrevemos anteriormente.

O primeiro aspecto se refere ao fato de que, antes da formação, as professoras, sujeitos deste estudo apresentavam conhecimento limitado sobre os significados das frações, pois trabalhavam apenas com o significado partetodo. Além disso, observamos que elas desconheciam os demais significados (quociente e razão), cuja exploração é recomendada nos documentos oficiais da educação, e se utilizavam apenas das ideias de partição na resolução de qualquer situação. É importante salientar que esses aspectos foram apontados também nas pesquisas de Garcia Silva (2007), Monteiro Cervantes (2010), dentre outras. Porém, percebemos que ao participar da formação, as docentes superaram, pelo menos em parte, tais dificuldades e ampliaram seus conhecimentos, como mostra o depoimento de uma das professoras investigadas, quando revela que passou a “[...] compreender o que significava 
parte-todo, quociente e razão, pois eu nunca havia aprendido e agora percebo claramente o que significa cada um deles" (professora Renata).

O segundo aspecto que gostaríamos de apontar é que as professoras não dominavam os invariantes operatórios e, ao final da formação, apresentaram maior clareza quanto à compreensão de ordem, equivalência e conservação da unidade de referência.

O terceiro aspecto está relacionado à metodologia. Observamos que as limitações do conhecimento do conteúdo também reduziam as possibilidades metodológicas, uma vez que antes de participar desta investigação, as professoras abordavam o tema, exclusivamente, por meio de situações parte-todo e focavam no procedimento de dupla contagem, corroborando os resultados de várias pesquisas já referidas anteriormente.

Porém, ao analisar o observado nas aulas ministradas por elas, um ano após a formação, pudemos perceber que, de maneira geral, as professoras ainda introduziram a fração por meio de uma situação parte-todo. Todavia, diferentemente do que ocorria antes da participação na formação, acrescentaram à apresentação da representação fracionária a utilização explícita da divisão, referindo-se, dessa forma, ao significado quociente. Nesse sentindo, podemos afirmar que houve, para esse grupo de professoras, a preocupação em relacionar os conhecimentos das ideias contidas em um significado e no outro.

Os resultados evidenciados corroboram a base teórica adotada na análise desta pesquisa, conhecimentos cuja combinação do domínio do conteúdo matemático com a compreensão de questões relacionadas ao ensino de tal conteúdo - nesse caso, sobre os diferentes significados da fração e seus invariantes - é fundamental para a eficácia no ensino da matemática (BALL; THAMES; PHELPS, 2008; SHULMAN, 1986).

Podemos afirmar também que alguns conhecimentos, como o conhecimento de conteúdo e de ensino (capacidade de relacionar diferentes significados e elaborar estratégias de intervenção), foram adquiridos pelas professoras no decorrer da formação. Porém, acreditamos, da mesma forma que Serrazina (2010), que o conhecimento profissional das professoras será ampliado ao longo do tempo à medida que elas, no contexto escolar e de outras formações, dialoguem com diferentes experiências vivenciadas. 
As evidências aqui descritas foram percebidas quando analisamos as contribuições da formação reveladas no trabalho desenvolvido por elas em sala de aula um ano após a intervenção. Analisando as atividades planejadas pelas três professoras, foi possível perceber que elas relacionaram as ideias presentes nos dois significados da fração que foram abordados no âmbito da formação.

Sendo assim, a partir da análise dos resultados obtidos por meio da observação dessa atividade, pudemos concluir que o processo formativo, de maneira geral, trouxe contribuições para o conhecimento profissional docente dos sujeitos investigados, uma vez que eles modificaram a sua prática por meio da abordagem do conceito de fração utilizando os dois significados discutidos e estabelecendo relações importantes entre eles.

Todavia, vale ressaltar que, em virtude do tempo restrito destinado à investigação, neste estudo observamos somente a aula introdutória sobre o tema frações. Consideramos ser importante que outras pesquisas estabeleçam relações entre a formação e a prática docente analisando todas as aulas destinadas ao ensino dessa temática. 


\title{
Inputs from a continuing education course observed in teachers' pedagogical practice
}

\begin{abstract}
The purpose of this article is to put in relief inputs from a continuing education course for teachers' pedagogical practices when teaching fractions to Elementary School first years' students. The education course took place in the context of Observatório da educação [Education Observatory] with a group of teachers from the State of São Paulo public school system. The quantitative nature investigation was made in three steps: teachers were asked to complete preliminary questionnaires, an intervention was made, then an interview and finally they were observed in classroom situation. What we show here is an analysis of classes conducted by three participants in the course one year after their education was over. We could observe changes on how teachers started approaching content concerning the exploration of ideas related to the meaning of quotient from part-wholes situations, establishing important relationships between the two meanings discussed earlier. We concluded that formation provided a significant input to knowledge (re)building about this concept by teachers under exam conditions.
\end{abstract}

Keywords: Mathematics education. Teaching fractions. Teacher education. Teaching practice. 
BALL, Débora Loewenberg; THAMES, Mark Hoover; PHELPS, Geoffrey. Content knowledge for teaching: what makes it special? Journal of Teacher Education, v. 59, n. 5, p. 389-407, 2008.

BEHR, Merlyn J.; LESH, Richard; POST, Thomas R.; SILVER, Edward. A. Rational number concepts. In: LESH, R.; LANDAU, M. (Ed.). Acquisition of mathematics concepts and processes. New York: Academic Press. p. 91126. 1983.

; WACHSMUTH, I.; POST, Thomas R.; LESH, Richard. Order and equivalence of rational numbers: a clinical teaching experiment. Journal for Research in Mathematics Education, v. 15, n. 5, p. 323-341, 1984.

CAMPOS, Tânia Maria Mendonça; JAHN, Ana Paula; LEME DA SILVA, Maria Célia; SILVA, Maria José Ferreira da. Lógica das equivalências. Relatório de pesquisa não publicado. São Paulo: PUC, 1995.

Sobre o ensino e aprendizagem de frações. In: CONFERENCIA INTERAMERICANA DE EDUCACIÓN MATEMÁTICA, 13., 2011, RECIFE. ANAIS... DISPONIIVEL EM: 〈http://www.cimm.ucr.ac.cr/ocs/index.php/xiii_ ciaem/xiii_ciaem/paper/viewFile/2896/1194>.ACESSO EM: 25 MAR. 2013.

CANOVA, Raquel Factore. Um estudo das situações parte-todo e quociente no ensino e aprendizagem do conceito de fração. 2013. 199 f. Tese (Doutorado em Educação Matemática)-Universidade Bandeirante Anhanguera de São Paulo, São Paulo, 2013.

CARDOSO, Paula; MAMEDE, Ema. Considerações sobre o ensino-aprendizagem do conceito de fracção à luz de um estudo com alunos do $6^{0}$ ano do ensino básico. In: CONGRESSO INTERNACIONAL GALEGO-PORTUGUÊS DE PSICOPEDAGOGIA, 10., 2009, BRAGA. ACTAS... BRAGA: UNIVERSIDADE DO MINHO, 2009.

DAMICO, Alécio. Uma investigação sobre a formação inicial de professores de matemática para o ensino de números racionais no ensino fundamental. 2007. 313 f. Tese (Doutorado em Educação Matemática)-Pontifícia Universidade Católica de São Paulo, São Paulo, 2007.

GARCIA SILVA, Angélica A. Fontoura. 0 desafio do desenvolvimento profissional docente: análise da formação continuada de um grupo de 
professores das séries iniciais do ensino fundamental, tendo como objeto de discussão o processo do ensino e aprendizagem de frações. 2007. 308 f. Tese (Doutorado em Educação Matemática)-Pontifícia Universidade Católica de São Paulo, São Paulo, 2007.

MACHADO, Nilson José. 0 pirulito do pato. São Paulo: Scipione, 2003.

MAMEDE, Ema. The effects of situations on children's understanding of fractions. 2007. Tese (Ph.D. não publicada)-Oxford Brookes University, Oxford, 2007.

MONTEIRO CERVANTES, Patrícia de Barros. Uma formação continuada sobre as frações. 2010. 86 f. Dissertação (Mestrado em Educação Matemática)Universidade Bandeirante Anhanguera de São Paulo, São Paulo, 2010.

NUNES, Terezinha; BRYANT, Peter. Crianças fazendo matemática. Porto Alegre: Artes Médicas, 1997.

; BRYANT, Peter; PRETZLIK, Ursula; HURRY, Jane. The effect of situations on children's understanding of fractions. Trabalho apresentado no encontro da British Society for Research on the Learning of Mathematics, Oxford, Reino Unido, 2003.

; BRYANT, Peter; PRETZLIK, Ursula; BELL, Daniel; EVANS, Deborah; Wade, Joanna. La compréhension des fractions chez les enfants. In: MERRI, Maryvonne. (Ed.) Activité humaine et conceptualisation. Toulouse: Presses Universitaires du Mirail, 2007. p. 255-262.

; BRYANT, Peter. Key understandings in mathematics learning. Paper 3: understanding rational numbers and intensive quantities. Nuffield Foundation, 2009. Disponível em: «nuffield foundation.org/reports〉. Acesso em: 15 jun. 2013.

PEREIRA, Marcelo Dias. Um estudo sobre interpretações das diretrizes curriculares para o curso de licenciatura em matemática por uma instituição federal de São Paulo. 2013, 271 f. Tese (Doutorado em Educação Matemática)-Universidade Bandeirante Anhanguera de São Paulo, São Paulo, 2013.

RODRIGUES, Wilson Roberto. Números racionais: um estudo das concepções dos alunos após o estudo formal. 2005. 247 f. Dissertação (Mestrado em Educação Matemática)-Pontifícia Universidade Católica de São Paulo, São Paulo, 2005. 
SERRAZINA, Maria de Lurdes. Reflexão, conhecimento e práticas lectivas em matemática num contexto de reforma curricular no $1^{0}$ ciclo. Quadrante, Lisboa, v. 8, p. 139-163, 1999.

. A formação contínua de professores em matemática: o conhecimento e a supervisão em sala de aula e a sua influência na alteração das práticas. International Journal for Studies in Mathematics Education, v. 2, n. 1, p. 1-23, 2010. Disponível em: 〈http://periodicos.uniban.br/index.php/JIEEM/article/ viewFile/112/92>. Acesso em: 19 out. 2013.

SHULMAN, Lee. Those who understand: knowledge growth in teaching. Educational Researcher, American Educational Research Association, v. 15, n. 2, p. 4-14, fev. 1986.

STREEFLAND, L. Search for the roots of ratio: Some thoughts on the long term learning process (towards ... a theory). Part I: Reflections on a teaching experiment. Educational Studies in Mathematics, v. 15, n. 4, p. 327-348, 1984.

Fractions in Realistic Mathematics Education: A Paradigm of Developmental Research. Norwell, MA: Kluwer Academic Publishers, 1991.

Charming fractions or fractions being charmed? In: NUNES, T.; BRYANT, P. (Eds.). Learning and Teaching Mathematics: an international perspective. Hove, Reino Unido: Psychology Press, 1997. p. 347-372.

VERGNAUD, Gérard. La théorie des champs conceptuels. Recherches en Didactique des Mathématiques, v. 10, n. 23, p. 133-170, 1990a.

. Epistemology and psicology of Matematics Education. In: NESHER, P., KILPATRICK, J. (Eds.) Mathematics and Cognition: A research synthesis by International Group for the Psychology of Mathematics Education. Cambridge: Cambridge University Press. p. 14-30, 1990b.

- Teoria dos campos conceituais. In: NASSER, L. (Ed.) SEMINÁRIO INTERNACIONAL DE EDUCAÇÃO MATEMÁTICA DO RIO DE JANEIRO, 1. 1993, RIO DE JANEIRO. ANAIS... RIO DE JANEIRO, 1993. P. 1-26.

RECEBIDO: Novembro de 2014.

APROVADO: Março de 2015. 